\title{
Virtual Reality Technology in Complex Medical Rehabilitation of Patients with Disabilities (Review)
}

\author{
DOI: $10.17691 / \mathrm{stm} 2018.10 .4 .21$
}

Received January 18, 2018

M.G. Volovik, DSc, Leading Researcher, Department of Functional Diagnostics, University Clinic;

V.V. Borzikov, Junior Researcher, Department of Functional Diagnostics, University Clinic;

A.N. Kuznetsov, Junior Researcher, Department of Functional Diagnostics, University Clinic;

D.I. Bazarov, Junior Researcher, Counseling and Rehabilitative Department, University Clinic;

A.G. Polyakova, MD, DSc, Senior Researcher, Counseling and Rehabilitation Department, University Clinic

Privolzhsky Research Medical University, 10/1 Minin and Pozharsky Square, Nizhny Novgorod, 603950, Russia

The review is devoted to integration of innovative virtual reality technologies in the complex of medical rehabilitation of patients with disabilities. The analysis of data presented in modern domestic and foreign literature proves the effectiveness of using these technologies for recovery of impaired motor functions in patients of various ages with nervous and musculoskeletal system pathologies and gives evidence of their corrective effect on neurophysiological motor deficiency. Evaluation of the achieved results from the perspective of evidence-based medicine confirms the feasibility of using a personalized approach to targeting and controlling the dosage of virtual technologies in the complex of rehabilitation measures.

Key words: virtual reality; rehabilitation; motor functions.

\section{Introduction}

The problem of rehabilitation of people with disabilities is relevant worldwide. According to the UN, there are about 450 million people with physical and mental disabilities. Among the Russian population, there are $7.8 \%$ of individuals with motor and cognitive disabilities due to injuries, musculoskeletal system and nervous system diseases, most of whom are workingage people [1]. This harms the country's economy, the loss measuring in tens of billions of rubles per year, and urges to seek and develop innovative multidisciplinary technologies able to improve effectiveness of complex rehabilitation measures [2].

Today, technologies that influence the brain through virtual reality (VR) are being actively developed. According to numerous data, their use increases medical rehabilitation efficacy in terms of both time and quality of the achieved results [3-10].

\section{The notion of virtual reality. VR technology development}

Virtual reality is a computer-generated simulation of real-world environment, reproduction of any situation through sensations (visual, auditory, olfactory, haptic etc.) in order to induce responses [11]. American computer artist Myron Krueger was the first to introduce the concept of artificial reality in the late 1960s. Immersion in VR is achieved through a coding language known as VRML (Virtual Reality Modeling Language). VR technologies use interactive simulation with VR headsets or glasses, projectors and sensor gloves. Moreover, there is multisensory stimulation (visual, auditory or haptic) in different variants: passive (watching videos) or active (the user manipulates the image of his own body - "avatar" or specific objects within the virtual scenario) using feedback from the computer calculating the results of user actions [12-16]. Multisensory training

Corresponding author: Mikhail G. Volovik, e-mail: afanassy@mail.ru 
in the virtual environment for physical rehabilitation was proposed by Australian physiotherapists Carr and Shepherd in 1982 [17].

In the late 1960s, VR was reported to be capable of reconstructing and training alpha-activity of the brain in order to enhance relaxation, which was used to assist patients with uncontrolled epilepsy [18]. In 1993, psychiatrist Lemson put forward the idea of using VR in rehabilitation of patients with various phobias and anxiety disorders [19]. At about the same time, the group of Williford described the decrease in acrophobia manifestations when using VR [20, 21]. Later, this approach was used in treatment of itching [22], pain syndromes [23, 24], depression, insomnia, post-traumatic stress disorder in the military [25, 26]. The potential of VR technology is highly appreciated in children with autism spectrum disorders [27-30] and in patients with Parkinson's disease [31], Alzheimer's disease [32], multiple sclerosis [33], etc. Nowadays, VR is increasingly used for rehabilitation after stroke [34-38]. The entertaining effect of immersion in VR distracts the patient's attention from painful procedures, reduces anxiety, discomfort or dissatisfaction with treatment [39].

In Russia, VR therapy in rehabilitation treatment of patients with motor disorders developed alongside with the methods of robotic mechanotherapy [40-42]. This approach is based on the fundamental mechanisms of motion physiology established by classics of national physiology Bernstein and Anokhin. When studied from the standpoint of evidence-based medicine, VR technologies proved to be highly effective in recovery of walking function $[9,43]$ and upper limb motor function [44-46]. Movements recover more successfully and physical activity increases in such patients due to training in a VR environment that is very close to the real world, higher motivation and active participation of patients in rehabilitation [47-49].

Traditional physiotherapeutic methods (therapeutic gymnastics and mechanotherapy) do not always involve active training of the patient's motor skills, while VR with its unique ability to reproduce almost any environment and provide feedback involves the patient in the training process with similar movement parameters, the patient being able to realize and correct his mistakes when performing movements [50-53]. VR creates an opportunity to improve motor skills more effectively in the same context as in real life owing to three key elements necessary for training motor functions (repeated stimulation, sensory feedback, patient motivation) [54, 55].

The use of VR in neurorehabilitation showed that recovery of motor deficits depends on activation of brain plasticity mechanisms, including changes in the primary sensorimotor cortex and in the additional motor area $[53,56,57]$. This knowledge allows us to expand the range of nosologies in which VR helps achieve significant results.

\section{VR neurorehabilitation \\ for motor functional recovery in patients after stroke}

One of the most promising areas of integrating VR in the rehabilitation complex is elimination of stroke consequences [58-60]. Most often, VR therapy is used in the long-term rehabilitation period of poststroke patients [61-63], although the literature data show the advantages of early VR rehabilitation using interactive games that increase motivation for therapy and programs with tactile feedback contributing to the recovery of sensory functions and preventing the development of potential complications [64, 65].

The results of including VR in the complex of rehabilitation measures for motor disorders in post-stroke patients are often ambivalent from the perspective of evidence-based medicine. For example, there were no statistically significant differences between treatment outcomes in the group of patients undergoing rehabilitation with the YouGrabber VR system (YouRehab, Switzerland) - game software simulating training in the gym - and in the control group with traditional therapy, although the results were slightly worse in the latter [66]. Functional contribution to motor deficit compensation similar to traditional rehabilitation methods was observed when using the Reh@City VR system (NeuroRehabLab, Portugal). It is a virtual simulation of a city where memory, attention, and solution of visual-spatial tasks are integrated to perform various daily activities [52]. As described in the study [67], in the early post-stroke period, patients used the Sixense VR system (USA) and rehabilitation game software with an avatar on the screen synchronized with the patient's movements. The authors reported improvement in sensorimotor function, but the differences between the main and control groups of patients appeared to be insignificant.

At the same time, a number of studies have demonstrated progressive improvement in quality and increase in the range of movements (for example, using VR in combination with rehabilitation exoskeleton for shoulder, elbow and wrist joints, enabling movements with seven degrees of freedom, support of the paretic arm, registration of movement kinematics and grip strength for feedback control) [49]. Promising results have been obtained in the work of Kiper et al. [68] where enhanced feedback in a virtual environment was used to restore upper limb dysfunction after stroke. Gesturecontrolled VR game consoles (Nintendo Wii; Nintendo, Japan; Xbox Kinect; Microsoft, USA) have demonstrated high efficiency in motor rehabilitation [69], especially for improving upper limb functions [70].

In general, interaction combining visual and tactile (haptic) stimulation appeared to be the most effective. For example, Yin et al. [71] investigated the effect of cycling exercises using VR on improving the balance in patients after stroke. The VR system used included 
bilateral pedal force sensors and a dynamometer platform, analyzed the collected data to provide the patient with feedback in the form of a virtual car, thereby training the affected side. The authors showed that strength increased by $22 \%$ and the balance improved by $29 \%$ after a cycle of such exercises. Similar rehabilitation principle is described in the work of Flowers et al. [72].

Gross data on present-day use of VR technologies for targeted motor rehabilitation of the upper limb functions after cerebral circulation disorders are given in a number of domestic articles [73-75]. Such basic motor functions of the hand as the ability to accurately reach the object, manipulate it, and coordinate the movements of both hands are primarily impaired in patients with motor disorders of central origin. The use of VR technologies can partially compensate for these disorders: difficulties in dosing muscle effort, for example, in finger flexion and extension [73] as well as muscle weakness, interarticular coordination disorders and the sequence of activation of different muscle groups [74].

A great number of recent studies have shown the efficacy of applying VR technologies for rehabilitation of patients with post-stroke motor disorders in the upper limbs, whereas the sources available provide no works focusing on the use of VR for rehabilitation of patients with the consequences of frequent limb injuries complicated by developing peripheral neuropathies (complex regional pain syndrome, etc.). Besides, as we have already mentioned, in a number of studies where such commercial VR systems as Sixense [67] or YouGrabber [66] were used in complex rehabilitation therapy of patients with motor disorders, the results showed no significant differences as compared to groups of patients undergoing conventional rehabilitation. The reason for this may be inaccurate selection of visual stimuli applied through 3D glasses or a panoramic screen, while neurorehabilitation requires the whole range of afferent stimuli [25]. This suggests that further research and development in this area remain relevant and search for more effective VR technologies as well as new evidence-based methods of verifying and predicting their application results should continue.

\section{VR technology in rehabilitation of children}

One of the promising directions in correcting the coordination and accuracy of limb movements is the use of VR as an additional method of rehabilitation in children with cerebral palsy [4]. Numerous works focusing on the use of VR technologies in such children are devoted to both technological and medical aspects of rehabilitation $[5,6,76]$. The most common system used in treatment of cerebral palsy is Virtual Rehab (USA), a rehabilitation platform designed to restore motor function of the limbs using commercially available sensors Microsoft Kinect (USA) and Leap Motion (USA) as well as video game technology for telerehabilitation. For example, a virtual environment has been developed on the basis of open source platform Unity 3D. A child with cerebral palsy can interact with the environment in real time using the Leap Motion sensor that detects and tracks hand and finger movements. At the same time, combined EEG recording with MindWave device (NeuroSky, USA) allows monitoring the patient's clinical progress in real time taking into account the differences in the levels of attention and relaxation [77].

Virtual reality in Microsoft Kinect sensor therapy proved to be effective in improving exercise performance and physical activity [5]. VR rehabilitation was found to have potentially positive effect on the manner of walking, balance, muscle strength and general motor skills in children with cerebral palsy [78]. Turning treatment into a game increases the child's attention when performing certain exercises in rehabilitation compared to conventional treatment $[79,80]$ and, most importantly, it is possible to use VR technologies at home [8, 81, 82]. The authors of these and other studies (for example, [83]) are optimistic about enhancing the conventional treatment with VR as an alternative play tool for cognitive and motor rehabilitation of children including those with multiple disorders. In literature, we have found no reports on the methods of remote instructor-assisted online sessions with the use of VR headsets for motor-disabled children, whereas similar systems for adult patients are being developed [84].

The study of Nikolenko et al. [85] presents developed by the authors complex for rehabilitation of children with progressive muscular dystrophy based on modern technologies of VR gaming, the efficacy of which was scientifically grounded and proved taking into consideration the existing principles of rehabilitation in children with this severe pathology. The technique can significantly improve motor functions, quality of life and ensure rehabilitation availability.

\section{VR technologies in rehabilitation of patients with consequences of injuries to the musculoskeletal system and the nervous system}

One of the most difficult problems of rehabilitation in patients with motor disorders is recovery of lost functions after spinal cord injury. The results of the latest studies [86-88] suggest the feasibility of using VR for rehabilitation of these patients. Evaluation of visual feedback effect in exercises with interactively controlled avatar on gait improvement in patients with spinal cord injury [89] showed that movement speed was significantly higher with fewer attempts compared to tests where only static scenes were demonstrated. Dimbwadyo-Terrer et al. [48] studied effectiveness of the VR system Toyra (Spain) in recovery of the upper limb function in people with tetraplegia caused by spinal cord injury. The course of rehabilitation involved VR games based on performing daily activities (eating, combing hair, or washing the face) with three difficulty levels. 
Despite the absence of statistically significant differences in rehabilitation results between these patients and the control group that underwent conventional rehabilitation treatment, they were more motivated and expressed willingness to carry on using the system Toyra.

Other researchers also remarked on positive dynamics when using VR technologies in patients after spinal injury [90-93]. For example, when studying VR effect on improving the driving ability in patients with spinal cord injury, it was observed that rehabilitation of driving skills in VR conditions made significant progress even when the consequences of spinal injury were severe [94].

Introducing VR technologies in the complex of rehabilitation measures in patients with loss of upper limb movements due to brain injuries is a very important factor in the process of retraining motor skills [95]. Conventional approaches in such cases are unable to solve the problem of neuroplasticity completely, while rehabilitation methods with the use of VR providing feedback can improve these processes [96-98].

Different task complexity levels can be the key factor for effective rehabilitation using VR, when the situation is modeled motivating patients to surpass their own results. For example, when developing movements using the Nintendo Wii game console (Japan) with a peripheral device that tracks the body position and movements (Balance Board, Nintendo of Korea), it was found that the effect of using the VR system in patients after knee surgery did not depend on knee injury severity, but was determined by consistent complication of tasks [99].

The use of wearable sensors contributed to successful integration of VR into the rehabilitation system of patients with frozen shoulder syndrome [100]. Rehabilitation treatment including a set of exercises, hot compresses, interference therapy consisted of sessions with VR for 40 min twice a week during 4 weeks. As a result, the authors of the study revealed a significant increase in the range of shoulder joint movements and strength of the upper limb muscles.

Recently, there have been published a few works focusing on the benefits of using VR technology in rehabilitation of patients with consequences of sports injuries (for example, the knee joint in the postoperative period) [101].

\section{Conclusion}

Technologies based on the use of virtual environment provide optimal conditions for recovery of motor deficits in patients with motor disorders, haptic feedback contributes to the recovery of sensory functions and interactive games increase motivation for therapy. However, to ensure safety of patients, especially children, there should be requirements for thorough evaluation of possible complications resulting from the use of VR technologies. A personalized approach is required in each case taking into account individual adaptive and compensatory capabilities of the body, assessing the adequacy of mental responses and controlling physiological functions of patients in their interaction with the virtual environment.

There are currently available software variants providing the possibility to include monitoring registration of various physiological parameters in mobile VR solutions, wearable devices connected to a smartphone. Muñoz et al. [102] have developed a mobile complex of virtual reality with built-in biological feedback based on the use of signals from the patient: heart rate, EEG and electromyography obtained through wearable sensors and transmitted to the smartphone via Bluetooth. These signals are used to control real-time virtual environment created on the basis of Unity 3D, while the EmoCat Rescue game developed by the authors based on the PhysioVR framework facilitates acquisition, streaming and recording of physiological signals. In this case, the smartphone is used as a screen for screenless virtual reality glasses and as a personal server for data transmission [102, 103]. Making virtual reality a mobile and economically accessible technology, such approaches represent the trends in development of VR rehabilitation in the near future and provide the basis for its large-scale introduction into medical practice.

Study funding. This study was not supported by any financial sources.

Conflict of interests. The authors have no conflict of interests to disclose.

\section{References}

1. Bryantseva N.V., Sulim O.N. Social and legal issues for people with disabilities. Uspekhi $v$ khimii $i$ khimicheskoy tekhnologii 2012; 9(138): 55-58.

2. Razumov A.N., Melnikova E.A. The modern approaches to the prognostication of rehabilitation of the patients after stroke on an individual basis: a review of the literature and the results of original investigations. Voprosy kurortologii, fizioterapii i lechebnoi fizicheskoi kul'tury 2015; 92(6): 11-16, https://doi.org/10.17116/kurort2015611-16.

3. Saposnik G., Levin M.; Outcome Research Canada (SORCan) Working Group. Virtual reality in stroke rehabilitation a meta-analysis and implications for clinicians. Stroke 2011; 42(5): 1380-1386, https://doi.org/10.1161/strokeaha. 110.605451.

4. Legkaya E.F., Khodasevich L.S., Polyakova A.V. The informational technologies for the comprehensive rehabilitation of the patients presenting with juvenile cerebral palsy (a review). Voprosy kurortologii, fizioterapii i lechebnoi fizicheskoi kul'tury 2016; 93(2): 53-58, https://doi.org/10.17116/ kurort2016253-58.

5. Bonnechère B., Jansen B., Omelina L., Degelaen M., Wermenbol V., Rooze M., Van Sint Jan S. Can serious games be incorporated with conventional treatment of children with cerebral palsy? A review. Res Dev Disabil 2014; 35(8): 1899 1913, https://doi.org/10.1016/j.ridd.2014.04.016.

6. Chen Y.P, Lee S.Y., Howard A.M. Effect of virtual reality on upper extremity function in children with cerebral palsy: 
a meta-analysis. Pediatr Phys Ther 2014; 26(3): 289-300, https://doi.org/10.1097/pep.0000000000000046.

7. Dascal J., Reid M., IsHak W.W., Spiegel B., Recacho J., Rosen B., Danovitch I. Virtual reality and medical inpatients: a systematic review of randomized, controlled trials. Innov Clin Neurosci 2017; 14(1-2): 14-21.

8. Miller K.J., Adair B.S., Pearce A.J., Said C.M., Ozanne E., Morris M.M. Effectiveness and feasibility of virtual reality and gaming system use at home by older adults for enabling physical activity to improve health-related domains: a systematic review. Age Ageing 2014; 43(2): 188-195, https:// doi.org/10.1093/ageing/aft194.

9. Sidiakina I.V., Dobrushina O.R., Liadov K.V., Shapovalenko T.V., Romashin O.V. The role of evidencebased medicine in the neurorehabilitation: the innovative technologies (a review). Voprosy kurortologii, fizioterapii $i$ lechebnoi fizicheskoi kul'tury 2015; 92(3): 53-56, https://doi. org/10.17116/kurort2015353-56.

10. Wang Q., Markopoulos P., Yu B., Chen W., Timmermans A. Interactive wearable systems for upper body rehabilitation: a systematic review. J Neuroeng Rehabil 2017; 14(1): 20, https://doi.org/10.1186/s12984-017-0229-y.

11. Riener R., Harders M. Virtual reality in medicine. London: Springer; 2012, https://doi.org/10.1007/978-1-4471-4011-5.

12. Abadía M.F., Quintana M.S., Calvo P.Á.M. Application of topographical capture techniques for modelling virtual reality: from the static object to the human figure. In: Virtual technologies for business and industrial applications: innovative and synergistic approaches. IGI Global; 2011; p. 181-200, https://doi.org/10.4018/9781615206315.ch011.

13. Moya S., Grau S., Tost D., Campeny R., Ruiz M. Animation of 3D avatars for rehabilitation of the upper limbs. In: Third International Conference on Games and Virtual Worlds for Serious Applications. IEEE; 2011; p. 168-171, https://doi. org/10.1109/vs-games.2011.32.

14. Zimmerli L., Jacky M., Lünenburger L., Riener R., Bolliger M. Increasing patient engagement during virtual reality-based motor rehabilitation. Arch Phys Med Rehabil 2013; 94(9): 1737-1746, https://doi.org/10.1016/j.apmr. 2013.01.029.

15. Pietrzak E., Cotea C., Pullman S. Using commercial video games for upper limb stroke rehabilitation: is this the way of the future? Top Stroke Rehabil 2014; 21(2): 152-162, https://doi.org/10.1310/tsr2102-152.

16. lamsakul K., Pavlovcik A.V., Calderon J.I., Sanderson L.M. Project heaven: preoperative training in virtual reality. Surg Neurol Int 2017; 8: 59, https://doi.org/10.4103/sni. sni_371_16.

17. Carr J.H., Shepherd R.B. Motor relearning programme for stroke. Rockville: Aspen Publishers; 1983.

18. Kamiya J. The first communications about operant conditioning of the EEG. J Neurother 2011; 15(1): 65-73, https://doi.org/10.1080/10874208.2011.545764.

19. Lemson R. Virtual therapy of anxiety disorders. CyberEdge Journal 1994; 4(2): 1-28.

20. Williford J., Hodges L., North M., North S. Relative effectiveness of virtual environment desensitization and imaginal desensitization in the treatment of acrophobia. In: Proceedings graphic interface. Toronto, ON: Canadian HumanComputer Communications Society; 1993; p. 162.

21. Rothbaum B.O., Hodges L.F., Kooper R., Opdyke D., Williford J.S., North M. Effectiveness of computer-generated (virtual reality) graded exposure in the treatment of acrophobia.
Am J Psychiatry 1995; 152(4): 626-628, https://doi. org/10.1176/ajp.152.4.626.

22. Leibovici V., Magora F., Cohen S., Ingber A. Effects of virtual reality immersion and audiovisual distraction techniques for patients with pruritus. Pain Res Manage 2009; 14(4): 283 286, https://doi.org/10.1155/2009/178751.

23. Keefe F.J., Huling D.A., Coggins M.J., Keefe D.F., Rosenthal M.Z., Herr N.R. Virtual reality for persistent pain: a new direction for behavioral pain management. Pain 2012; 153(11): 2163-2166, https://doi.org/10.1016/j. pain.2012.05.030.

24. Jones T., Moore T., Choo J. The impact of virtual reality on chronic pain. PLoS One 2016; 11(12): e0167523, https:// doi.org/10.1371/journal.pone.0167523.

25. Tegza V.Y., Dyakonov I.F., Ovchinnikov B.V., Shpilenya L.S., Palekhova O.V. Modern and advanced technology medical and psychological rehabilitation of military personnel. Medline.ru 2015; 16: 659-668. URL: http://www. medline.ru/public/art/tom16/art60.html.

26. Lewis G.N., Rosie J.A. Virtual reality games for movement rehabilitation in neurological conditions: how do we meet the needs and expectations of the users? Disabil Rehabil 2012; 34(22): 1880-1886, https://doi.org/10.3109/09638288.20 12.670036 .

27. Georgescu A.L., Kuzmanovic B., Roth D., Bente G., Vogeley $\mathrm{K}$. The use of virtual characters to assess and train nonverbal communication in high-functioning autism. Front Hum Neurosci 2014; 8: 807, https://doi.org/10.3389/ fnhum.2014.00807.

28. Parsons S. Authenticity in virtual reality for assessment and intervention in autism: a conceptual review. Educational Research Review 2016; 19: 138-157, https://doi.org/10.1016/j. edurev.2016.08.001.

29. Forbes P.A.G., Pan X., Hamilton A.F. de C. Reduced mimicry to virtual reality avatars in autism spectrum disorder. J Autism Dev Disord 2016; 46(12): 3788-3797, https://doi. org/10.1007/s10803-016-2930-2.

30. Duffield T.C., Parsons T.D., Landry A., Karam S., Otero T., Mastel S., Hall T.A. Virtual environments as an assessment modality with pediatric ASD populations: a brief report. Child Neuropsychol 2017, 24(8): 1129-1136, https://doi. org/10.1080/09297049.2017.1375473.

31. Dockx K., Bekkers E.M.J., Van den Bergh V., Ginis P., Rochester L., Hausdorff J.M., Mirelman A., Nieuwboer A. Virtual reality for rehabilitation in Parkinson's disease. Cochrane Database Syst Rev 2016; 12: CD010760, https://doi. org/10.1002/14651858.cd010760.pub2.

32. García-Betances R.I., Arredondo Waldmeyer M.T., Fico G., Cabrera-Umpiérrez M.F. A succinct overview of virtual reality technology use in Alzheimer's disease. Front Aging Neurosci 2015; 7: 80, https://doi.org/10.3389/ fnagi.2015.00080.

33. Massetti T., Trevizan I.L., Arab C., Favero F.M., RibeiroPapa D.C., de Mello Monteiro C.B. Virtual reality in multiple sclerosis - a systematic review. Mult Scler Relat Disord 2016; 8: 107-112, https://doi.org/10.1016/j.msard.2016.05.014.

34. Wüest S., van de Langenberg R., de Bruin E.D. Design considerations for a theory-driven exergame-based rehabilitation program to improve walking of persons with stroke. Eur Rev Aging Phys Act 2014; 11(2): 119-129, https:// doi.org/10.1007/s11556-013-0136-6.

35. Lledó L.D., Díez J.A., Bertomeu-Motos A., Ezquerro S., Badesa F.J., Sabater-Navarro J.M., García-Aracil N. 
A comparative analysis of $2 \mathrm{D}$ and $3 \mathrm{D}$ tasks for virtual reality therapies based on robotic-assisted neurorehabilitation for post-stroke patients. Front Aging Neurosci 2016; 8: 205, https://doi.org/10.3389/fnagi.2016.00205.

36. Schmid L., Glässel A., Schuster-Amft C. Therapists' perspective on virtual reality training in patients after stroke: a qualitative study reporting focus group results from three hospitals. Stroke Res Treat 2016; 2016: 6210508, https://doi. org/10.1155/2016/6210508.

37. Saposnik G. Virtual reality in stroke rehabilitation. In: Ovbiagele B. (editor). Ischemic stroke therapeutics. Springer, Cham; 2016; p. 225-233, https://doi.org/10.1007/978-3-31917750-2_22.

38. Brunner I., Skouen J.S., Hofstad H., Aßmus J., Becker F., Sanders A.-M., Pallesen H., Kristensen L.Q., Michielsen M., Thijs L., Verheyden G. Virtual reality training for upper extremity in subacute stroke (VIRTUES). Neurology 2017; 89(24): 2413-2421, https://doi.org/10.1212/ wnl.0000000000004744.

39. Rooij M., Lobel A., Owen H., Smit N., Granic I. DEEP: a biofeedback virtual reality game for children atrisk for anxiety. In: Proceedings of the $2016 \mathrm{CHI}$ Conference Extended Abstracts on Human Factors in Computing Systems CHI EA '16. ACM Press; 2016, p. 1989-1997, https://doi. org/10.1145/2851581.2892452.

40. Chernikova L.A., Piradov M.A., Suponeva N.A., Chervyakov A.V., Klochkov A.S., Mokienko O.A., Lyukmanov R.Kh., Poydasheva A.G., Avdyunina I.A. Vysokotekhnologichnye metody neyroreabilitatsii pri zabolevaniyakh nervnoy sistemy. $\mathrm{V}$ kn.: Nevrologiya XXI veka: diagnosticheskie, lechebnye $i$ issledovatel'skie tekhnologii [High-tech methods of neurorehabilitation for diseases of the nervous system. In: Neurology of the XXI century: diagnostic, therapeutic and research technologies]. Pod red. Piradova M.A., Illarioshkina S.N., Tanashyan M.M. [Piradov M.A., Illarioshkin S.N., Tanashyan M.M. (editors)]. Moscow: ATMO; 2015; p. 274-331.

41. Chernikova L.A., Suponeva N.A., Klochkov A.S., Khizhnikova A.E., Lyukmanov R.H., Gnedovskaya E.V., Yankevich D.S., Piradov M.A. Robotic and mechanotherapeutic technology to restore the functions of the upper limbs: prospects for development (review). Sovremennye tehnologii v medicine 2016; 8(4): 222-230, https://doi.org/10.17691/ stm2016.8.4.27.

42. Gordleeva S.Yu., Lukoyanov M.V., Mineev S.A., Khoruzhko M.A., Mironov V.I., Kaplan A.Ya., Kazantsev V.B. Exoskeleton control system based on motor-imaginary braincomputer interface. Sovremennye tehnologii v medicine 2017; 9(3): 31-38, https://doi.org/10.17691/stm2017.9.3.04.

43. Moreira M.C., de Amorim Lima A.M., Ferraz K.M., Benedetti Rodrigues M.A. Use of virtual reality in gait recovery among post stroke patients - a systematic literature review. Disabil Rehabil Assist Technol 2013; 8(5): 357-362, https://doi. org/10.3109/17483107.2012.749428.

44. Laver K., George S., Thomas S., Deutsch J.E., Crotty M. Virtual reality for stroke rehabilitation. Stroke 2012; 43(2), https://doi.org/10.1161/strokeaha.111.642439.

45. Turolla A., Dam M., Ventura L., Tonin P., Agostini M., Zucconi C., Kiper P., Cagnin A., Piron L. Virtual reality for the rehabilitation of the upper limb motor function after stroke: a prospective controlled trial. J Neuroeng Rehabil 2013; 10: 85, https://doi.org/10.1186/1743-0003-10-85.

46. Piggott L., Wagner S., Ziat M. Haptic neurorehabilitation and virtual reality for upper limb paralysis: a review. Crit Rev Biomed Eng 2016; 44(1-02): 1-32, https://doi.org/10.1615/ critrevbiomedeng.2016016046.

47. Regenbrecht H., Hoermann S., McGregoret G., Dixon B., Franz E., Ott C., Hale L., Schubert T., Hoermann J. Visual manipulations for motor rehabilitation. Computers \& Graphics 2012; 36(7): 819-834, https://doi.org/10.1016/j. cag.2012.04.012.

48. Dimbwadyo-Terrer I., Gil-Agudo A., Segura-Fragoso A., de los Reyes-Guzmán A., Trincado-Alonso F., Piazza S., Polonio-López B. Effectiveness of the virtual reality system Toyra on upper limb function in people with tetraplegia: a pilot randomized clinical trial. Biomed Res Int 2016; 2016: 6397828, https://doi.org/10.1155/2016/6397828.

49. Grimm F., Naros G., Gharabaghi A. Closed-loop task difficulty adaptation during virtual reality reach-to-grasp training assisted with an exoskeleton for stroke. Front Neurosci 2016; 10: 518, https://doi.org/10.3389/fnins.2016.00518.

50. Bohil C.J., Alicea B., Biocca F.A. Virtual reality in neuroscience research and therapy. Nat Rev Neurosci 2011; 12(12): 752-762, https://doi.org/10.1038/nrn3122.

51. Luu T.P., He Y., Brown S., Nakagome S., ContrerasVidal J.L. A closed-loop brain computer interface to a virtual reality avatar: gait adaptation to visual kinematic perturbations. In: International Conference on Virtual Rehabilitation (ICVR). IEEE; 2015, p. 30-37, https://doi.org/10.1109/icvr.2015. 7358598.

52. Faria A.L., Andrade A., Soares L., Badia S.B. Benefits of virtual reality based cognitive rehabilitation through simulated activities of daily living: a randomized controlled trial with stroke patients. J Neuroeng Rehabil 2016; 13(1): 96-107, https://doi. org/10.1186/s12984-016-0204-z.

53. Teo W.P., Muthalib M., Yamin S., Hendy A.M., Bramstedt K., Kotsopoulos E., Perrey S., Ayaz H. Does a combination of virtual reality, neuromodulation and neuroimaging provide a comprehensive platform for neurorehabilitation? - A narrative review of the literature. Front Hum Neurosci 2016; 10: 284, https://doi.org/10.3389/ fnhum.2016.00284.

54. Pereira M.E., Rueda M.F., Diego A.I.M., de la Cuerda R.C., de Mauro A., Miangolarra Page J.C. Use of virtual reality systems as proprioception method in cerebral palsy: clinical practice guideline. Neurologia 2014; 29(9): 550 559, https://doi.org/10.1016/j.nrleng.2011.12.011.

55. Yeh S.C., Huang M.C., Wang P.C., Fang T.Y., Su M.C., Tsai P.Y., Rizzo A. Machine learning-based assessment tool for imbalance and vestibular dysfunction with virtual reality rehabilitation system. Comput Methods Programs Biomed 2014; 16(3): 311-318, https://doi.org/10.1016/j. cmpb.2014.04.014.

56. You S.H., Jang S.H., Kim Y.H., Kwon Y.H., Barrow I., Hallett M. Cortical reorganization induced by virtual reality therapy in a child with hemiparetic cerebral palsy. Dev Med Child Neurol 2005; 47: 628-635, https://doi.org/10.1017/ s0012162205001234.

57. Basso Moro S., Bisconti S., Muthalib M., Spezialetti M., Cutini S., Ferrari M., Placidi G., Quaresima V. A semiimmersive virtual reality incremental swing balance task activates prefrontal cortex: a functional near-infrared spectroscopy study. Neuroimage 2014; 85: 451-460, https:// doi.org/10.1016/j.neuroimage.2013.05.031.

58. Bower K.J., Louie J., Landesrocha Y., Seedy P., Gorelik A., Bernhardt J. Clinical feasibility of interactive 
motion-controlled games for stroke rehabilitation. $J$ Neuroeng Rehabil 2015; 12(1): 63, https://doi.org/10.1186/s12984-0150057-x.

59. Levac D.E., Glegg S.M.N., Sveistrup H., Colquhoun H., Miller P., Finestone H., De Paul V., Harris J.E., Velikonja D. Promoting therapists' use of motor learning strategies within virtual reality-based stroke rehabilitation. PLOS One 2016; 11(12): e0168311, https://doi.org/10.1371/journal. pone.0168311.

60. Chen L., Lo W.L.A., Mao Y.R., Ding M.H., Lin Q.L., Li H., Zhao J.L., Xu Z.Q., Bian R.H., Huang D.F. Effect of virtual reality on postural and balance control in patients with stroke: a systematic literature review. Biomed Res Int 2016; 2016: 7309272, https://doi.org/10.1155/2016/7309272.

61. Cameirão M.S., Badia S.B., Duarte E., Frisoli A., Verschure P.F. The combined impact of virtual reality neurorehabilitation and its interfaces on upper extremity functional recovery in patients with chronic stroke. Stroke 2012; 43(10): 2720-2728, https://doi.org/10.1161/ strokeaha.112.653196.

62. Yeh S.C., Lee S.H., Chan R.C., Chen S., Rizzo A. A virtual reality system integrated with robot-assisted haptics to simulate pinch-grip task: motor ingredients for the assessment in chronic stroke. Neurorehabilitation 2014; 35(3): 435-449.

63. Lloréns R., Gil-Gómez J.A., Alcañiz M., Colomer C., Noé E. Improvement in balance using a virtual reality-based stepping exercise: a randomized controlled trial involving individuals with chronic stroke. Clin Rehabil 2015; 29(3): 261268, https://doi.org/10.1177/0269215514543333.

64. Bao X., Mao Y., Lin Q., Qiu Y., Chen S., Li L., Cates R.S., Zhou S., Huang D. Mechanism of kinect-based virtual reality training for motor functional recovery of upper limbs after subacute stroke. Neural Regen Res 2013; 8(31): 2904-2913.

65. Iosa M., Morone G., Fusco A., Castagnoli M., Fusco F.R., Pratesi L., Paolucci S. Leap motion controlled videogame-based therapy for rehabilitation of elderly patients with subacute stroke: a feasibility pilot study. Top Stroke Rehabil 2015; 22(4): 306-316, https://doi.org/10.1179/107493 $5714 z .0000000036$.

66. Stockley R.C., O'Connor D.A., Smith P., Moss S., Allsop L., Edge W. A mixed methods small pilot study to describe the effects of upper limb training using a virtual reality gaming system in people with chronic stroke. Rehabil Res Pract 2017; 2017: 9569178, https://doi. org/10.1155/2017/9569178.

67. Yin C.W., Sien N.Y., Ying L.A., Chung S.F., Tan May Leng D. Virtual reality for upper extremity rehabilitation in early stroke: a pilot randomized controlled trial. Clin Rehabil 2014; 28(11): 1107-1114, https://doi. org/10.1177/0269215514532851.

68. Kiper P., Agostini M., Luque-Moreno C., Tonin P., Turolla A. Reinforced feedback in virtual environment for rehabilitation of upper extremity dysfunction after stroke: preliminary data from a randomized controlled trial. Biomed Res Int 2014; 2014: 752128, https://doi.org/10.1155/2014/752128.

69. Lohse K.R., Hilderman C.G., Cheung K.L., Tatla S., Van Der Loos H.F. Virtual reality therapy for adults poststroke: a systematic review and meta-analysis exploring virtual environments and commercial games in therapy. PLOS One 2014; 9(3): e93318, https://doi.org/10.1371/journal. pone.0093318.

70. Thomson K., Pollock A., Bugge C., Brady M
Commercial gaming devices for stroke upper limb rehabilitation: a systematic review. Int $J$ Stroke 2014; 9(4): 479-488, https://doi.org/10.1111/ijs.12263.

71. Yin C., Hsueh Y.H., Yeh C.Y., Lo H.C., Lan Y.T. A virtual reality-cycling training system for lower limb balance improvement. Biomed Res Int 2016; 2016: 9276508, https:// doi.org/10.1155/2016/9276508.

72. Flowers A., Herve J.-Y. BioPresence: a virtual reality biofeedback system. 2018.

73. Chernikova L.A., loffe M.E., Kurganskaya M.E., Mokienko O.A., Katsuba N.A., Ustinova K.I., Prokopenko R.A., Frolov A.A. The use of the virtual reality technology for the restoration of movements of the paretic hand after stroke. Fizioterapiya, bal'neologiya, reabilitatsiya 2011; 3: 3-7.

74. Khizhnikova A.E., Klochkov A.S., KotovSmolenskiy A.M., Suponeva N.A., Chernikova L.A. Virtual reality as an upper limb rehabilitation approach. Human Physiology 2017; 43(8): 855-862, https://doi.org/10.1134/ s0362119717080035.

75. Zakharov A.V., Pyatin V.F., Kolsanov A.V., Poverennova I.E., Segreeva M.S., Khivintseva E.V., Korovina E.S., Kucepalova G.U. Using virtual reality as a method of accelerated rehabilitation among the patients after stroke. Nauka i innovatsii v meditsine 2016; 3: 62-66.

76. Galvin J., Levac D. Facilitating clinical decisionmaking about the use of virtual reality within pediatric motor rehabilitation: describing and classifying virtual reality systems. Dev Neurorehabil 2011; 14(2): 112-122, https://doi.org/10.310 9/17518423.2010.535805.

77. de Oliveira J.M., Fernandes R.C., Pinto C.S., Pinheiro P.R., Ribeiro S., de Albuquerque V.H. Novel virtual environment for alternative treatment of children with cerebral palsy. Comput Intell Neurosci 2016; 2016: 8984379, https://doi. org/10.1155/2016/8984379.

78. Cho C., Hwang W., Hwang S., Chung Y. Treadmill training with virtual reality improves gait, balance, and muscle strength in children with cerebral palsy. Tohoku J Exp Med 2016; 238(3): 213-218, https://doi.org/10.1620/tjem.238.213.

79. Howcroft J., Klejman S., Fehlings D., Wright V., Zabjek K., Andrysek J., Biddiss E. Active video game play in children with cerebral palsy: potential for physical activity promotion and rehabilitation therapies. Arch Phys Med Rehabil 2012; 93(8): 1448-1456, https://doi.org/10.1016/j. apmr.2012.02.033.

80. Ni L., Fehlings D., Biddiss E. Clinician and child assessment of virtual reality therapy games for motor rehabilitation of cerebral palsy. Arch Phys Med Rehabil 2014; 95(10): e105, https://doi.org/10.1016/j.apmr.2014.07.323.

81. Gagliardo P., Ferreiro T., Izquierdo R., Mas G., Penades V., Chirivella J. NeuroAtHome: a software platform of clinically designed videogames specifically designed for the motor rehabilitation of stroke patients. Abstracts 2014. Brain Injury 2014; 28(5-6): 517-878, https://doi.org/10.3109/0269905 2.2014.892379

82. Chen Y.P., Garcia-Vergara S., Howard A.M. Effect of a home-based virtual reality intervention for children with cerebral palsy using super pop VR evaluation metrics: a feasibility study. Rehabil Res Pract 2015; 2015: 812348, https://doi.org/10.1155/2015/812348.

83. Green D., Wilson P.H. Use of virtual reality in rehabilitation of movement in children with hemiplegia - a multiple case study evaluation. Disabil Rehabil 2012; 34(7): 593-604, https://doi.org/10.3109/09638288.2011.613520. 
84. Ongvisatepaiboon K., Chan J.H., Vanijja V. Smartphone-based tele-rehabilitation system for frozen shoulder using a machine learning approach. In: 2015 IEEE Symposium Series on Computational Intelligence. IEEE; 2016, https://doi.org/10.1109/ssci.2015.120.

85. Nikolenko N., Goncharova O.V., Artemyeva S.B., Achkasov E.E., Litvinova E.B. Use of virtual reality game systems in rehabilitation of children with progressive muscular dystrophies. Sportivnaya meditsina: nauka i praktika 2014; 4: 90-97.

86. Rahman Y.A., Hoque M.M., Zinnah K.I., Bokhary I.M. Helping-hand: a data glove technology for rehabilitation of monoplegia patients. In: 9th International Forum on Strategic Technology (IFOST). IEEE; 2014; p. 199-204, https://doi. org/10.1109/ifost.2014.6991104.

87. Roosink M., Mercier C. Virtual feedback for motor and pain rehabilitation after spinal cord injury. Spinal Cord 2014; 52(12): 860-866, https://doi.org/10.1038/sc.2014.160.

88. Pozeg P., Palluel E., Ronchi R., Solca M., AlKhoudairy A.W., Jordan X., Kassouha A., Blanke O. Virtual reality improves embodiment and neuropathic pain caused by spinal cord injury. Neurology 2017; 89(18): 1894-1903, https:// doi.org/10.1212/wnl.0000000000004585.

89. Roosink M., Robitaille N., Jackson P.L., Bouyer L.J., Mercier C. Interactive virtual feedback improves gait motor imagery after spinal cord injury: an exploratory study. Restor Neurol Neurosci 2016; 34(2): 227-235, https://doi.org/10.3233/ rnn-150563.

90. Villiger M., Bohli D., Kiper D., Pyk P., Spillmann J., Meilick B., Curt A., Hepp-Reymond M.C., HotzBoendermaker S., Eng K. Virtual reality-augmented neurorehabilitation improves motor function and reduces neuropathic pain in patients with incomplete spinal cord injury. Neurorehabil Neural Repair 2013; 27(8): 675-683, https://doi. org/10.1177/1545968313490999.

91. Mao Y., Chen P., Li L., Huang D. Virtual reality training improves balance function. Neural Regen Res 2014; 9(17): 1628-1634, https://doi.org/10.4103/1673-5374.141795.

92. Nas K., Yazmalar L., Şah V., Aydin A., Öneş K. Rehabilitation of spinal cord injury. World J Orthop 2015; 6(1): 8-16, https://doi.org/10.5312/wjo.v6.i1.8.

93. Rammo R., Schwalb J.M. Comment: is virtual reality a useful adjunct to rehabilitation after spinal cord injury? Neurology 2017; 89(18): 1902, https://doi.org/10.1212/ Whl. 0000000000004607.

94. Sung W.H., Chiu T.Y., Tsai W.W., Cheng H., Chen J.J. The effect of virtual reality-enhanced driving protocol in patients following spinal cord injury. J Chin Med Assoc 2012; 75(11): 600-605, https://doi.org/10.1016/j.jcma.2012.08.004.
95. Wright W.G., McDevitt J., Appiah-Kubi K.O. A portable virtual reality balance device to assess mild traumatic brain injury symptoms: a pilot validation study. In: International Conference on Virtual Rehabilitation (ICVR). IEEE; 2015, https://doi.org/10.1109/icvr.2015.7358591.

96. Levin M.F., Weiss P.L., Keshner E.A. Emergence of virtual reality as a tool for upper limb rehabilitation: incorporation of motor control and motor learning principles. Phys Ther 2015; 95(3): 415-425, https://doi.org/10.2522/ ptj.20130579.

97. Levin M., Magdalon E.C., Michaelsen S.M., Quevedo A. Quality of grasping and the role of haptics in a 3D immersive virtual reality environment in individuals with stroke. IEEE Trans Neural Syst Rehabil Eng 2015; 23(6): 1047-1055, https://doi.org/10.1109/tnsre.2014.2387412.

98. Fedotchev A.I., Parin S.B., Polevaya S.A., Velikova S.D. Brain-computer interface and neurofeedback technologies: current state, problems and clinical prospects (review). Sovremennye tehnologii $v$ medicine 2017; 9(1): 175-184, https://doi.org/10.17691/stm2017.9.1.22.

99. Lee M., Suh D., Son J., Kim J., Eun S.D., Yoon B.C. Patient perspectives on virtual reality-based rehabilitation after knee surgery: importance of level of difficulty. $J$ Rehabil Res Dev 2016; 53(2): 239-252, https://doi.org/10.1682/ jrrd.2014.07.0164.

100. Lee S.H., Yeh S.C., Chan R.C., Chen S., Yang G., Zheng L.R. Motor ingredients derived from a wearable sensor-based virtual reality system for frozen shoulder rehabilitation. Biomed Res Int 2016; 2016: 7075464, https:// doi.org/10.1155/2016/7075464.

101. Gokeler A., Bisschop M., Myer G.D., Benjaminse A., Dijkstra P.U., van Keeken H.G., van Raay J.J., Burgerhof J.G., Otten E. Immersive virtual reality improves movement patterns in patients after ACL reconstruction: implications for enhanced criteria based return-to-sport rehabilitation. Knee Surg Sports Traumatol Arthrosc 2016; 24(7): 2280-2286, https://doi. org/10.1007/s00167-014-3374-x.

102. Muñoz J.E., Paulino T., Vasanth $H_{\text {., }}$ Baras $K$. PhysioVR: a novel mobile virtual reality framework for physiological computing. In: IEEE 18th International Conference on e-Health Networking, Applications and Services (Healthcom). IEEE; 2016, https://doi.org/10.1109/ healthcom.2016.7749512.

103. Muñoz J.E., Gouveia E.R., Cameirão M., Bermudez I., Badia S. The biocybernetic loop engine: an integrated tool for creating physiologically adaptive videogames. In: Proceedings of the 4th International Conference on Physiological Computing Systems. Madrid, Spain; 2017; p. 45-54, https:// doi.org/10.5220/0006429800450054. 